\title{
$\angle$ Research Square \\ Burden and determinants of chronic kidney disease among diabetic patients in Ethiopia: A systematic Review and Meta-analysis, 2020
}

\author{
Tadesse Tolossa ( $\nabla$ yadanotolasa@gmail.com ) \\ Wollega University \\ Getahun Fetensa \\ Wollega University \\ Bikila Regassa \\ Wollega University \\ Mekdes Tigistu \\ Wollega University \\ Ginenus Fekadu \\ Wollega University \\ Merga Besho \\ Wollega University \\ Daniel Bekele \\ Diredawa University
}

Research article

Keywords: Kidney disease, nephropathy, diabetic, Ethiopia

Posted Date: April 15th, 2020

DOI: https://doi.org/10.21203/rs.3.rs-22449/v1

License: (9) This work is licensed under a Creative Commons Attribution 4.0 International License.

Read Full License 


\section{Abstract}

Background Chronic kidney disease (CKD) among diabetic patients is becoming a global health burden with a high economic cost to health systems. Its incidence is increased at higher rate in low income countries including Ethiopia. In Ethiopia, there is no national representative evidence on burden and determinants of chronic kidney disease among diabetic patients. Therefore, this review aimed to estimates the pooled burden and determinants of chronic kidney disease among diabetic patients. Methods Published articles from various electronic databases such as Pub Med, Google scholar, CINAHL, Scopes, Cochrane library, the Web of Science and African Journals Online were accessed. Also, unpublished studies from Addis Ababa digital library were identified. All observational studies that were conducted on the burden and determinants of chronic kidney disease among diabetic patients were included. Data were extracted on the Microsoft excel spreadsheet and analyzed using STATA 14.1 version. A random-effects model was used to estimate the pooled estimate with a $95 \%$ confidence interval $(\mathrm{Cl})$. Forest plots were used to visualize the presence of heterogeneity and estimate the pooled burden and determinants of chronic kidney disease among diabetic patients. The presence of publication bias was assessed by funnel plots and Egger's statistical tests. Results Published (163) and unpublished (2) literature were identified from several databases and digital library, of which ten articles were selected for final meta-analysis. Significant heterogeneity was observed across studies (I $2=84.6 \%$, which suggests random-effects model to estimate pooled burden. The analysis found that the pooled burden of chronic kidney disease among diabetic patients was $17.55 \%$ (95\% Cl: 14.23-20.88). Being hypertensive patient, type II DM and staying with DM for greater than 10 years had positive significant association with chronic kidney disease. Conclusion The current review revealed a higher burden of chronic kidney diseases among diabetic patients in Ethiopia. Presence of hypertension, type of diabetes mellitus and staying with diabetes for longer duration were found to be independent determinants of chronic kidney disease among diabetic patients. For better control of chronic kidney disease, integrated management of hypertension and DM should be designed with special focus on chronic diabetic patients.

\section{Background}

Chronic kidney disease (CKD) is a state in which the kidneys cannot filter blood to the body as a normal kidney, and which result in accumulation of excess fluid and waste in the body [1]. Worldwide, in 2016 there were more than 21 million new cases of CKD per year showing an increase of CKD by $88.76 \%$, 276 million prevalent cases showing an increase of CKD by $86.95 \%$, nearly 1.2 million deaths due to CKD indicating an increase of the disease by $98.02 \%$ from 1990 [2]. Different studies showed the developing countries, particularly African regions are the highest risk for CKD burden and its advancement to end stage renal disease $[3,4]$. Currently, most developing countries are experiencing rapid epidemiological transitions and are provoked with the double burden of communicable and non-communicable diseases [5]. This dual burden has led to a consequential rise in the number of people affected by CKD on the developing countries, especially sub Saharan Africa $[2,6]$. Around $63 \%$ of chronic kidney disease are found in low and lower-middle-income countries [2]. 
Over the last decades, diabetes followed by hypertension are considered as the two prominent drivers of chronic kidney disease (CKD) [2, 7]. Diabetic nephropathy/chronic kidney disease is one of the most common complications of diabetes. Globally, diabetes mellitus accounts $50.62 \%$ of the overall increase in chronic kidney disease disability-adjusted life-years (DALYs). The increase in burden of chronic kidney disease due to diabetes and elevated blood pressure happened at a much faster rate in developing countries than in high-income countries [2]. A systematic review conducted in sub Saharan Africa showed that $95 \%$ of diabetic patients develop kidney disease after 10 years from diabetes diagnosis, estimated $35 \%$ may develop end-stage renal disease after 5 years, and 18\% die from kidney disease after 20 years of diabetic diagnosis [7].

Chronic kidney disease results with increased premature mortality, development of end-stage renal disease and need to renal replacement therapy, cardiovascular diseases, and rising health-care costs [7]. For examples, with large numbers of end stage renal disease patients in SSA, treatment and care for chronic kidney disease is very challenging due to inadequate facilities and lack of funding for dialysis [8] CKD is a global health burden with a high economic cost to health systems [9]. In high income countries, about $0.03 \%$ of their population spend more than $2-3 \%$ of their annual health-care budget on the treatment of end-stage renal disease [10]. This due to higher risk of infection, incapability of patient and family to work as well as it's burden of death [11].

Glucose homeostasis is highly disturbed in patients with diabetic and kidney disease, those are exposed to a high risk of both hyperglycemia and hypoglycemia. High or low glycemic levels are both associated with increased illness and shortened survival in this category of patients [12].It is an independent risk factor for hypoglycemia due to decreased renal gluconeogenesis, deranged metabolic pathways (including altered metabolism of medications) and decreased insulin clearance [12, 13]. As well it augments the risk of hypoglycemic events already present in people with diabetes [13]. Until recently, diabetic nephropathy accompanied by retinopathy, hypertension and progression to advanced kidney failure which will be very difficult to reverse [14].

The incidence and prevalence of diabetes was increased globally in past decades. Due to advancement in technology, adoption of western lifestyles, changes in the living environment, and the rapid urbanization, the complication related to DM especially diabetic retinopathy and diabetic nephropathy was increased $[4,14]$. Diabetic is of risk for inducing kidney disease [15].

Globally, factors such as increase in age [7, 16, 17], type II DM [17], hypertensive patients [7, 17-19], poor knowledge about the disease [18], living with diabetes for longer duration [7, 17, 18], increased BMI [17] and obesity [7] are important contributing factors for the occurrence of chronic kidney disease.

Blood sugar controls are very important for delaying onset of diabetic complication specifically for patients with chronic kidney disease. Delaying occurrence of complication requires knowledge of how kidney disease will affects metabolism and how medication can be safely used [20].The management of diabetes is predicated on the basis of reducing hyperglycemia to improve hyperglycemic symptoms, will prevent the onset, and slow down progression of renal complications over time [21]. In another way, the 
longer duration of living with DM, the probability of having kidney disease will be increased [22]. Contrarily in developing countries like Ethiopia, this reality is not well addressed and that is why this review and meta-analysis is required. In addition, there is no nationally representative data on burden of chronic kidney disease among diabetic patients in Ethiopia. Therefore, this systematic review and metaanalysis was aimed estimates the pooled burden of chronic kidney disease and its determinants among diabetic patients in Ethiopia.

Assessing the pooled burden and determinants of CKD led us to develop and design intervention which used to reduce burden of the disease, particularly in resource-limited settings such as Ethiopia. The implications of the findings of our study are for national policymakers, program managers, and nongovernmental organizations to reduce burden of CKD among diabetic patients.

\section{Methods}

\section{Study design and setting}

A systematic review and meta-analysis were conducted to assess the pooled burden and determinants of chronic kidney disease among diabetic patients in Ethiopia. Ethiopia is a land locked country found in horn of Africa with estimated population of 109 million. It shares the boundary with Eritrea to the north, Djibouti to the north east, Somalia to the east, Kenya to the south, South Sudan to the west and Sudan to the north west [23].

\section{Search strategy and review process}

A published and unpublished study on the burden and determinants of chronic kidney disease among diabetic patients in Ethiopia were conducted in this meta-analysis. Endnote version X7.2 was used to maintain and manage citation and facilitate the review process [24]. On initial step of the search process, the presence of the existing systematic review and meta-analysis on similar topic was checked by extensive search of literatures. All pertinent published studies in the following major databases; PubMed, Google scholar, CINAHL, Scopes, Cochrane library, the Web of Science and African Journals Online were involved in the review. The reference lists of identified studies were also reviewed to find additional articles. Unpublished studies were retrieved from the official website of Addis Ababa University electronic database. Pre-identified search terms were used to allow a comprehensive search strategy that included all the relevant studies. The search terms "chronic kidney disease" OR "renal failure" OR" nephropathy" AND" diabetes mellitus" AND" diabetes complications "OR" chronic complication of DM "AND" diabetic patients "AND" Ethiopia" were used. The search of the literature was conducted between the $10^{\text {th }}$ of December, 2019 to the $10^{\text {th }}$ of January,2020.

\section{Eligibility criteria}

\section{Inclusion criteria}


Participants: All diabetic patients regardless of age and types of DM

Study design: All observational study design (cross-sectional, case-control and cohort) were included.

Setting: Studies only conducted in Ethiopia

Study: All studies (published and unpublished) that were published in the form of journal articles, master's thesis, and PhD dissertation were included.

Language: Only English language was considered in this study

\section{Exclusion Criteria}

We excluded articles which were not fully accessible, after at least two-email contact with the principal authors of the study.

\section{Measurement of outcome variables}

The burden of chronic kidney disease among diabetic patients was the first outcome of the study. Chronic kidney disease was defined using glomerular filtration rate (eGFR) $<60 \mathrm{ml} / \mathrm{min} / 1.73 \mathrm{~m} 2)$ and presence of albuminuria [25]. The glomerular filtration rate (GFR) was estimated using Modification of Diet in Renal Disease (MDRD) and Cockcroft Gault equations [17]. Determinants of chronic kidney disease among diabetic patients was the second outcome of this study. For binary data (determinants of chronic kidney disease), the input variables required by "metan command" which contain the cells of $2 \times 2$ table; i.e., the number of individuals who did and did not experience the chronic kidney disease in the exposed and non-exposed groups for each study. All potential determinants which related with chronic kidney disease was determined using the odds ratio (OR) and calculated based on binary outcomes from the included primary studies. Sex of patients, hypertension, types of diabetes, family history of CKD, current alcohol consumption, duration of diabetes, and BMI were potential variables which selected in the analysis.

\section{Quality assessment and data abstraction}

To assess the quality of the data, the Joanna Briggs Institute Meta-Analysis of Statistics Assessment and Review Instrument (JBI-MAStARI) was used [24]. Two reviewers (Tadesse Tolossa and Getahun Fetensa) independently extracted the data using standardized data extraction checklist on Microsoft excel spread sheet. The systematic review and meta-analysis followed the Preferred Reporting Items for Systematic Review and Meta-Analyses (PRISMA) flow chart to identify and select relevant studies for this analysis [26]. At the beginning, literature was downloaded, supplemented to Endnotes version 7.2 reference management and duplicated literatures were excluded. Then, studies were screened and excluded by their titles and abstracts. Studies that were found to be non-pertinent to our study were excluded during this screening. After the literatures were excluded by their titles and abstracts, full text of the remaining literatures was assessed. The eligibility of the studies was evaluated based on pre-determined inclusion 
and exclusion criteria. For the first outcome variable (burden of chronic kidney disease among diabetic patients), checklist for data extraction contains the title, author name, year of publication, region, study design, sample size, response rate and a number of participants with cases. For the second outcome (determinants of chronic kidney disease), data were extracted in a format of two by two tables, and then the log OR was calculated based on the findings of the original studies (Table 1). After two data extractors performed the review, any discrepancy was resolved by including the third reviewer (BR) for a possible consensus.

\section{Data Analysis and heterogeneity}

After important information was extracted on Microsoft excel from each original studies, the data were exported to STATA for windows version 14 for analysis. Burden of chronic kidney disease with $95 \%$ confidence interval $(\mathrm{Cl})$ and $\mathrm{OR}$ of the association between chronic kidney disease among diabetic patients and its determinants were presented in the form of forest plot. Cochran $Q$ test (chi-squared statistic) and inverse variance $\left(I^{2}\right)$ statistic on forest plot were used to check heterogeneity among the included studies. Cochran's $Q$ statistical heterogeneity test is considered as statistically significant at $\mathrm{p} \leq$ 0.05. A random-effects model was used to estimate the pooled burden of chronic kidney disease among diabetic patients. For the second outcome, a fixed-effects model was computed in the absence of heterogeneity, and random effects model was used to estimate the Der Simonian and Laird's pooled effect in the presence of moderate to a high degree of heterogeneity. To identify source of heterogeneity, meta-regression was conducted using sample size and year of publication. In addition, subgroup analysis was performed using region where the studies were conducted and statistically significant results were declared in the presence of heterogeneity. The publication bias was checked by funnel plot. In addition, Egger's weighted regression and Begg's test was used to check the significance presence of publication bias at p-value of less than 0.05 [27].

\section{Results}

\section{Study selection}

A total 163 published and 2 unpublished literatures were identified from several electronic databases and Addis Ababa digital library, respectively. Of the total identified studies, 45 duplicates papers were removed and 97 records were removed by reviewing titles and abstracts. The full text of the remaining 23 studies were assessed and screened for eligibility. Thirteen studies were excluded because studies were not conducted in Ethiopia, outcome was not chronic kidney and participants were not diabetic patients. Finally, 10 articles which scored seven and above on the JBI quality appraisal eligibility criteria were included in the systematic review and meta-analysis. We used the Preferred Reporting Items for Systematic Reviews and Meta-Analyses (PRISMA) flow diagram to present the systematic review overview [26] (Figure 1).

\section{Features of included studies}


Of the total included studies, all were published articles except one study which was retrieved from gray literature [28]. Regarding to study design, eight studies were cross-sectional study design [16-19, 25, 2830], one case-control [31], and one retrospective cohort study design [32]. The studies were conducted from 2010 [29] to 2019 [18, 19] in various regions of the country. An overall 3091 diabetic patients were participated in this study. The sample sizes ranged from minimum of 163 [19] to maximum of 435 [32] participants from study conducted in Addis Ababa. Of the ten studies included in the final analysis, four in Addis Ababa [19, 28, 30, 32], two in Oromia region [18, 29], Two in Amhara region [16, 17], One in SNNP region [25] and One in Tigrai region [31] (Table 1).

Table 1: Summary of included studies regarding burden and determinants of CKD among diabetic patients in Ethiopia, 2020.

\begin{tabular}{|c|c|c|c|c|c|c|c|c|c|c|c|}
\hline S.N & Author & Year & Region & Study design & Study area & $\begin{array}{l}\text { Method of } \\
\text { estimating } \\
\text { eGFR }\end{array}$ & $\begin{array}{l}\text { CKD } \\
\text { definition }\end{array}$ & $\begin{array}{l}\text { Sample } \\
\text { size }\end{array}$ & $\begin{array}{l}\text { Response } \\
\text { rate }\end{array}$ & $\begin{array}{l}\text { No } \\
\text { of } \\
\text { CKD }\end{array}$ & $\begin{array}{l}\text { Burden } \\
\text { of CKD } \\
(95 \% \\
\text { CI) }\end{array}$ \\
\hline 1 & $\begin{array}{l}\text { Temesgen } \\
\text { F, et al.[25] }\end{array}$ & 2014 & SNNP & $\begin{array}{l}\text { Cross- } \\
\text { sectional }\end{array}$ & $\begin{array}{l}\text { Butajira } \\
\text { hospital }\end{array}$ & MDRD & $\begin{array}{l}\mathrm{eGFR}<60 \\
\mathrm{ml} / \mathrm{min} / 1.73 \\
\mathrm{~m} 2\end{array}$ & 214 & $100 \%$ & 39 & $\begin{array}{l}18.2 \\
(13.0 \\
23.4)\end{array}$ \\
\hline 2 & $\begin{array}{l}\text { Kidist R, et } \\
\text { al. [16] }\end{array}$ & 2017 & Amhara & $\begin{array}{l}\text { Cross- } \\
\text { sectional }\end{array}$ & $\begin{array}{l}\text { Felegehiwot } \\
\text { hospital }\end{array}$ & not stated & $\begin{array}{l}\mathrm{eGFR}<60 \\
\mathrm{ml} / \mathrm{min} / 1.73 \\
\mathrm{~m} 2\end{array}$ & 344 & $100 \%$ & 39 & $\begin{array}{l}11.3 \\
(7.9, \\
14.6)\end{array}$ \\
\hline 3 & $\begin{array}{l}\text { Kabaye K, } \\
\text { et al. [18] }\end{array}$ & 2019 & Oromia & $\begin{array}{l}\text { Cross- } \\
\text { sectional }\end{array}$ & JUMC & MDRD & $\begin{array}{l}\mathrm{eGFR}<60 \\
\mathrm{ml} / \mathrm{min} / 1.73 \\
\mathrm{~m} 2\end{array}$ & 208 & $100 \%$ & 54 & $\begin{array}{l}25.9 \\
(20.0 \\
31.9)\end{array}$ \\
\hline 4 & $\begin{array}{l}\text { Shawaneh } \\
\text { D M. et } \\
\text { al. [17] }\end{array}$ & 2018 & Amhara & $\begin{array}{l}\text { Cross- } \\
\text { sectional }\end{array}$ & UGH & MDRD & $\begin{array}{l}\mathrm{eGFR}<60 \\
\mathrm{ml} / \mathrm{min} / 1.73 \\
\mathrm{~m} 2\end{array}$ & 229 & $100 \%$ & 50 & $\begin{array}{l}21.8 \\
(16.4 \\
27.1)\end{array}$ \\
\hline 5 & $\begin{array}{l}\text { Dawit W, et } \\
\text { al.[29] }\end{array}$ & 2010 & Oromia & $\begin{array}{l}\text { Cross- } \\
\text { sectional }\end{array}$ & JUMC & not stated & $\begin{array}{l}\mathrm{eGFR}<60 \\
\mathrm{ml} / \mathrm{min} / 1.73 \\
\mathrm{~m} 2\end{array}$ & 305 & $100 \%$ & 48 & $\begin{array}{l}15.7 \\
(11.6, \\
19.8)\end{array}$ \\
\hline 6 & $\begin{array}{l}\text { M Gizaw, } \\
\text { et al.[30] }\end{array}$ & 2015 & $\mathrm{AA}$ & $\begin{array}{l}\text { Cross- } \\
\text { sectional }\end{array}$ & $\begin{array}{l}\text { Black Lion } \\
\text { Hospital }\end{array}$ & not stated & $\begin{array}{l}\text { eGFR }<60 \\
\mathrm{ml} / \mathrm{min} / 1.73 \\
\mathrm{~m} 2\end{array}$ & 418 & $100 \%$ & 39 & $\begin{array}{l}9.3 \\
(6.5 \\
12.1)\end{array}$ \\
\hline 7 & $\begin{array}{l}\text { Getahun C, } \\
\text { et al. [19] }\end{array}$ & 2019 & $\mathrm{AA}$ & $\begin{array}{l}\text { Cross- } \\
\text { sectional }\end{array}$ & $\begin{array}{l}\text { Black Lion } \\
\text { Hospital }\end{array}$ & MDRD & $\begin{array}{l}\mathrm{eGFR}<60 \\
\mathrm{ml} / \mathrm{min} / 1.73 \\
\mathrm{~m} 2\end{array}$ & 163 & $100 \%$ & 39 & $\begin{array}{l}23.9 \\
(17.3 \\
30.4)\end{array}$ \\
\hline 8 & $\begin{array}{l}\text { Meron M. } \\
\text { [28] }\end{array}$ & 2016 & $\mathrm{AA}$ & $\begin{array}{l}\text { Cross- } \\
\text { sectional }\end{array}$ & $\mathrm{AA}$ & $\begin{array}{l}\text { MDRD and } \\
\text { Cockcroft } \\
\text { Gault } \\
\text { equation }\end{array}$ & $\begin{array}{l}\mathrm{eGFR}<60 \\
\mathrm{ml} / \mathrm{min} / 1.73 \\
\mathrm{~m} 2\end{array}$ & 355 & $100 \%$ & 68 & $\begin{array}{l}19.1 \\
(15.0 \\
23.2)\end{array}$ \\
\hline 9 & $\begin{array}{l}\text { Solomon } \\
\text { H,et } \\
\text { al. [31] }\end{array}$ & 2017 & Tigrai & Case control & $\begin{array}{l}\text { Ayider } \\
\text { referral } \\
\text { hospital }\end{array}$ & not stated & $\begin{array}{l}\mathrm{eGFR}<60 \\
\mathrm{ml} / \mathrm{min} / 1.73 \\
\mathrm{~m} 2\end{array}$ & 420 & $100 \%$ & 84 & $\begin{array}{l}20.0 \\
(16.1 \\
23.8)\end{array}$ \\
\hline 10 & $\begin{array}{l}\text { Alemayehu } \\
\text { H, et al. } \\
{[32]}\end{array}$ & 2018 & $\mathrm{AA}$ & $\begin{array}{l}\text { Retrospective } \\
\text { follow up }\end{array}$ & $\begin{array}{l}\text { St. Paul's } \\
\text { Hospital }\end{array}$ & $\begin{array}{l}\text { Cockcroft- } \\
\text { Gault } \\
\text { equation }\end{array}$ & $\begin{array}{l}\mathrm{eGFR}<60 \\
\mathrm{ml} / \mathrm{min} / 1.73 \\
\mathrm{~m} 2\end{array}$ & 435 & $100 \%$ & 62 & $\begin{array}{l}14.2 \\
(10.9 \\
17.5)\end{array}$ \\
\hline
\end{tabular}

AA: Addis Ababa; CKD:Chronic Kidney Disease; eGFR: Glomular Filtration Rate; JUMC: Jimma University Medical College;MDRD: Modification of Diet in Renal Disease; SNNP: Southern Nation, nationalities and peoples; UGH: University of Gondar Hospital 


\section{Burden of chronic kidney disease among diabetic patients in Ethiopia}

In this meta-analysis, we found significant heterogeneity across studies $\left(I^{2}=84.6 \%, p=0.00\right)$, which is an indicator to use random effect-model to estimate the pooled burden of chronic kidney disease among diabetic patients. The findings of original studies indicated that there were uneven and inconclusive burden of chronic kidney disease among diabetic patients in Ethiopia. From forest plot the largest burden was observed in study conducted in Jimma University Medical Center (JUMC), Oromia region 25.9 (95\% Cl: 20.0, 31.9) [18] while the smallest burden was reported in Black Lion hospital, Addis Ababa 9.3 (95\% Cl: $6.5,12.1)$ [30].The pooled burden of chronic kidney disease among diabetic patients was $17.55 \%$ (95\%Cl: 14.23-20.88) (Figure 2).

Meta regression was computed to see underlying sources of heterogeneity using sample size and year of publication, but none of them showed a statistically significance presence of heterogeneity. Moreover, to minimize potential heterogeneity, subgroup analysis was conducted based on the region where the studies were conducted. Its result showed the highest burden in Oromia region while the smallest was seen in Addis Ababa (Figure 3).

To see for the presence of publication bias, graphical funnel plot and Egger's test at $5 \%$ significance level were computed (Figure 5). The asymmetric funnel plot indicates the presence of publication bias. In addition, Egger's and Begg's tests showed statistically significant presence of publication bias $(p=0.001$, 0.006), respectively (Table 2 ).

Table 2: Meta regression using sample size and year of publication to observe related heterogeneity on burden of CKD among diabetic patients in Ethiopia, 2019

\begin{tabular}{|l|l|l|}
\hline \multicolumn{1}{|c|}{. Variables } & Coefficients & p-value \\
\hline Publication Year & 0.0344531 & 0.309 \\
\hline Sample size & 0.0008549 & 0.058 \\
\hline
\end{tabular}

Sensitivity analyses of the studies were done to test the effect of a single study on the pooled result of remaining studies using random effect model. We found no strong suggestion for influence of individual study on remaining studies (Figure 4).

\section{Determinants of chronic kidney disease among diabetic patients in Ethiopia}

\section{Sex and chronic kidney disease among diabetic patients}

To see the effect of sex on chronic kidney disease among diabetic patients, six studies were included in meta-analysis [17-19, 28, 31, 32]. The pooled result showed that, there was no a statistically significant association between sex of the patients and chronic kidney disease among diabetic patients in Ethiopia (OR=0.89, 95\%, Cl: 0.70, 1.14) (Figure 6). 


\section{Hypertension and Chronic kidney disease among diabetic patients}

To observe the pooled effect of hypertension history on chronic kidney disease, five studies were selected in final meta-analysis $[17,19,28,31,32]$. Since, high heterogeneity was observed $\left(I^{2}=81.7, P=\right.$ value < 0.001), a random effects model was used to report the effect of hypertension on chronic kidney disease. Three studies $[17,19,31]$ showed the presence of a statistically significant association between hypertension and chronic kidney disease, while two studies [28,32] did not show a statistical significance association. The finding discovered that the odds of developing chronic kidney disease was 2.65 times more likely among hypertensive patients than non-hypertensive patients. $(\mathrm{OR}=2.65,95 \%, \mathrm{Cl}: 1.38,5.09)$ (Figure 7).

\section{Types of DM and chronic kidney disease among diabetic patients}

To compute the effect of types of DM on chronic kidney disease, three studies were selected for metaanalysis [17, 28, 31]. A random effects model was used to estimate the pooled effect of types of DM on chronic kidney disease $\left(I^{2}=73.1, P\right.$-value $\left.<0.024\right)$. Two of the included studies showed a statistically significance association $[17,31]$ while one of the study did not indicated a statistically significant between types of DM and chronic kidney disease [28]. The pooled result of the analysis revealed type I DM decrease the odds of developing chronic kidney disease by $67 \%$ as compared to type II DM (OR=0.33, 95\%, Cl: 0.14-0.76) (Figure 8).

\section{Family history of kidney disease and chronic kidney disease among diabetic patients}

Two studies were selected to observe effect of family history of kidney disease on chronic kidney disease among diabetic patients $[18,28]$. Both studies showed no statistically significant association between family history of kidney disease and chronic kidney disease among diabetic patients $(\mathrm{OR}=1.06,95 \% \mathrm{Cl}$ : $0.56,2.00$ ) (Figure 9).

\section{Alcohol consumption and chronic kidney disease among diabetic patients}

Four studies were included in final meta-analysis to see the effect of alcohol consumption on chronic kidney disease among diabetic patients $[17,28,31,32]$ of which, a single study showed significance association between alcohol consumption and chronic kidney disease [31]. The pooled result showed that there was no significance effect of consuming alcohol on developing kidney disease $(O R=0.98,95 \%$ Cl: 0.47, 2.06) (Figure 10).

\section{BMI and chronic kidney disease among diabetic patients.}

To identify the association between BMI and chronic kidney disease, four studies were selected for metaanalysis [17, 19, 28, 31]. One study showed statistically significant association [31] and three studies revealed no significant association between $\mathrm{BMI}$ and chronic kidney disease. The pooled finding uncovered no significant association between $\mathrm{BMI}$ and chronic kidney disease among diabetic patients (OR=1.70, 95\% Cl: 0.70, 4.14) (Figure 11). 


\section{Duration of DM and chronic kidney disease among diabetic patients}

Three studies were identified to see the effect of duration of patient stayed with DM on developing chronic kidney disease $[17,18,28]$. The pooled finding figures out that the duration of the patients stayed with DM were significantly associated with development of chronic kidney disease among diabetic patients. Being diabetic patients for less than 10 years decrease the odds of developing chronic kidney disease by $49 \%$ as compared to diabetic patients who stayed with DM for 10 years (OR=0.51, 95\%, Cl: 0.34-0.77) (Figure 12).

\section{Discussion}

The burden of chronic non communicable diseases (CNCDs) is increasing in Ethiopia. Different small scale studies are indicating the incremental pattern of CKD in diabetic patients in different regions of the country $[17,19,31]$. However, there is paucity of representative evidence to show the burden and the determinants of CKD among diabetic patients in Ethiopia.

The finding indicated that the magnitude of CKD among diabetic patients in Ethiopia ranges from 9.3\% (95\% Cl: $6.5-12.1)$ to $25.9 \%$ (95\% Cl: $20.0-31.9 \%$ ). The pooled magnitude of CKD was $17.55 \%$ (95\% Cl: 14.23-20.88) with significant heterogeneity across the studies. The result is relatively low when compared to the systematic review of diabetic nephropathy in Africa which ranged from $11 \%$ to $83.1 \%$ [7]. The observed difference might be due to the review includes studies from over 16 African countries.

Another analysis of systematic review on the burden of CKD among general population and high risk groups in Africa found the magnitude of CKD among diabetic patients ranging from $11 \%-90 \%$ with pooled prevalence of $24.7 \%$ ( $95 \% \mathrm{Cl}: 23.6 \%-25.7 \%$ ) which was higher than the result of current metaanalysis [8]. The discrepancy could be due to the difference in the number of studies included in the analysis.

Studies from Sub Sahara African (SSA) countries also indicated the increasing burden of CKD among diabetic patients. shortage of adequate funds and trained human resources as there is continuing 'brain drain' of health care workers from Africa to more prosperous countries of the world, lack of regional registries were among factors for the increasing burden of the disease [8, 33].

The current pooled burden of CKD among diabetic patients in this review was found to be lower than other studies. which is $35.5 \%$ and $24.6 \%$ in China [34,35] and $20.7 \%$ in Cape Town [36]. However, the current finding is higher than reports from Nigeria (7.8\%) [37], Malawi (1.4\%) [38], Indonesia (4\%) [39] and Sudan (13.3\%) [40]. This might be due to the difference in study design, sample size, criteria of selection of the study participants, study area.

The odds of developing CKD for those who had hypertension were increased more than two folds when compared to CKD patients without history of hypertension. This finding is in agreement with other results $[7,8,33,35,38,40]$. The possible explanation for this could be the under achievement of blood pressure 
targets that could attribute to early end organ damage and late presentation of medical care in patients with hypertension and diabetes mellitus $[7,33,41]$.This also pointed to the growing evidence for the existence of genetically determined and environmentally induced factors responsible for the high risk of damage to kidney, especially in countries like Ethiopia. Inadequate blood pressure control may explain the prevalence of CKD reviewed; however, poor renal function may also lead to an increased risk of blood pressure.

Types of diabetes mellitus was one of the prominent factors to contribute for the development of CKD among diabetic patients. Being type I diabetes mellitus decrease the odds of developing CKD among diabetic patients. Evidences indicated that an increased burden of type II diabetes mellitus in developing countries including Ethiopia is closely linked to an increase in obesity. Because, developing countries are experiencing rapid demographic and epidemiological transitions which is characterized by westernization of societies (plentiful foods, labor- saving machinery and longer lifespan) [42]. There is also the pathophysiological confirmation that type II DM differ from type I to be significantly associated with CKD. Micro/ macro albuminuria may be present when type II DM is diagnosed, reflecting its long lasting asymptomatic period and hypertension more commonly accompanies micro/ macro albuminuria in type II DM [43].

The odds of developing CKD among diabetic patients was greatly reduced in diabetic patients who stayed with DM for less than 10 years when compared to those who stayed with the diseases for more than 10 years. This study goes in line with other study results $[1,4,12]$. This could be explained as an increased burden of type II DM in the population and an improved survival of patients with type II DM patients. In another way, as the disease progress over time, -cell function and insulin secretion decreases. This in turn facilitate for advancement of CKD among the patients.

\section{Limitation of the study}

Even though the review will help as a paramount importance in contributing for providing recent evidence in Ethiopia, it has some limitations which need to be considered when used for further studies. The first and for most, relatively small sample size was used in almost all studies. Most of the studies included were cross sectional with only one study case control and retrospective cohort design each. All studies were health-facility based studies assessing diabetes mellitus patients on regular follow up or admitted which could hinder the generalizability of the study leaving aside the diabetic patients left undiagnosed in large population.

\section{Conclusion}

In conclusion, the current review indicated that there is high burden of CKD among diabetic patients in Ethiopia. Determinants of CKD among diabetic patients were presence of hypertension, type of diabetes mellitus and duration of time the patient stayed after diagnoses. For better control of chronic kidney disease, integrated management of hypertension and DM should be designed with special focus on chronic diabetic patients. A well designed surveillance of high blood pressure and hyperglycemia is a 
better way to prevent and control the disease. Primary health care structures of the country should focus on early detection, proper screening and management in order to reduce the effect of CKD on diabetic patients. Moreover, it is highly recommended to conduct a longitudinal study with representative samples both from health facility and community based at large to depict the clearly up dated data to influence policy makers and program planners at national and international level.

\section{Abbreviations}

BMI: Body Mass Index, Cl: Confidence Interval, CKD: Chronic Kidney Disease, CNCD: Chronic Non Communicable Disease, DM: Diabetes Mellitus; OR: Odd Ratio, SNNP-Southern Nation Nationalities and People, SSS: Sub-Saharan Africa

\section{Declarations}

\section{Ethical Approval and Consent to Participate}

Not applicable

\section{Consent to publish}

Not applicable

\section{Availability of Data and Materials}

All data analyzed during this study are included in the manuscript.

\section{Competing Interests}

The authors declare that they have no competing interests.

\section{Funding}

No funding was obtained for this study

\section{Authors' Contribution}

TT involved in developing proposal and statistical analysis. TT, GF, BR, GF, and MT involved in the design, selection of articles, and data extraction. TT, GF, DB, and MB involved in developing the initial drafts of the manuscript. All authors participated in the final preparation of manuscript and they approved the final draft of the manuscript for submission.

\section{Acknowledgments}

We would like to thank all authors of the studies included in this systematic review and meta-analysis. 


\section{Author Information}

${ }^{1 *}$ Department of Public Health, Institute of Health Sciences, Wollega University, Nekemte, Ethiopia.

${ }^{2}$ Department of Nursing, School of Nursing and Midwifery, Wollega University, Nekemte, Ethiopia.

${ }^{3}$ Department of Pharmacy, Institute of Health Sciences, Wollega University, Nekemte, Ethiopia.

${ }^{4}$ Department of Midwifery, School of Nursing and Midwifery, Wollega University, Nekemte, Ethiopia.

${ }^{5}$ Department of Statistics, College of Computational Science, Dire Dawa University, Dire Dawa, Ethiopia.

\section{Supporting Information}

\section{S1 File: PRISMA checklist}

\section{References}

1. (CDC), C.f.D.C.a.P., National Chronic Kidney Disease Fact Sheet, 2017, in US Department of Health and Human Services. 2017, US Department of Health and Human Services: Atlanta, GA.

2. Yan Xie, et al., Analysis of the Global Burden of Disease study highlights the global, regional, and national trends of chronic kidney disease epidemiology from 1990 to 2016. Kidney International 2018. 94: p. 567-581.

3. Peralta CA, et al., The Association of African Ancestry and elevated creatinine in the coronary artery risk development in young adults (CARDIA) study. Am J Nephrol, 2010. 31(3): p. 202-208.

4. Arnaud D. Kaze, et al., Burden of chronic kidney disease on the African continent: a systematic review and meta-analysis. BMC Nephrology, 2018. 19(125).

5. Daar AS, et al., Grand challenges in chronic non-communicable diseases. Nature, 2007. 450(7169): p. 494-6.

6. S, N., Burden of end-stage renal disease in sub-Saharan Africa. . Clin Nephrol, 2010. 74: p. 13-6.

7. Jean Jacques N Noubiap, Jashira Naidoo, and A.P. Kengne, Diabetic nephropathy in Africa: $A$ systematic review. World J Diabetes, 2015. 6(5): p. 759-773.

8. Naicker, S., End-stage renal disease in Sub-Saharan Africa. International Society of Nephrology, 2013. 3: p. 161-163.

9. Chala, G., T. Sisay, and Y. Teshome, Chronic Kidney Disease And Associated Risk Factors Among Cardiovascular Patients. International Journal of Nephrology and Renovascular Disease, 2019. 12: p. 205-211.

10. Valerie A Luyckx, Marcello Tonelli, and J.W. Stanifer, The global burden of kidney disease and the sustainable development goals. Bull World Health Organ, 2018. 96: p. 414-422. 
11. Wang, H.E., et al., Chronic Kidney Disease and Risk of Death from Infection. Am J Nephrol, 2011. 34: p. 330-336.

12. Pecoits-Filho, R., et al., Interactions between kidney disease and diabetes: dangerous liaisons. Diabetology \& Metabolic Syndrome, 2016. 8(50).

13. Alsahli, M. and J.E. Gerich, Hypoglycemia, Chronic Kidney Disease, and Diabetes Mellitus. Mayo Foundation for Medical Education and Research, 2014. 89(11): p. 1564-1571.

14. Martínez-Castelaoa, A., et al., ERBP guideline on management of patients with diabetes and chronic kidney disease stage 3B or higher. Metformin for all? n e f r o l o g i a, 2017. 37(6): p. 567-571.

15. Akokuwebe, M.E. and C. Odimegwu, Socioeconomic Determinants of Knowledge of Kidney Disease Among Residents in Nigerian Communities in Lagos State, Nigeria. Oman Medical Journal, 2019. 34(5): p. 444-455.

16. Kidist Reba Lebeta, Zeleke Argaw, and B.W. Birhane, Prevalence of Diabetic Complications and Its Associated Factors Among Diabetes Mellitus Patients Attending Diabetes Mellitus Clinics; Institution Based Cross Sectional Study. American Journal of Health Research, 2017. 5(2): p. 38-43.

17. Shewaneh Damtie, et al., Chronic Kidney Disease and Associated Risk Factors Assessment among Diabetes Mellitus Patients at A Tertiary Hospital, Northwest Ethiopia. Ethiop J Sci, 2018. 28(6).

18. KabayeKumela Goro, et al., Patient Awareness, Prevalence, and Risk Factors of Chronic Kidney Disease among DiabetesMellitus and Hypertensive Patients at Jimma UniversityMedical Center, Ethiopia. Hindawi, 2019.

19. Getahun Chala, Tariku Sisay, and Y. Teshome, Chronic Kidney Disease And Associated Risk Factors Among Cardiovascular Patients. International Journal of Nephrology and Renovascular Disease, 2019. 12: p. 205-211.

20. Hahr, A.J. and M.E. Molitch, Management of diabetes mellitus in patients with chronic Disease. Hahr and Molitch Clinical Diabetes and Endocrinology, 2015. 1(2).

21. Diabetiologist, A.o.B.C., Managing hyperglycaemia in patients with diabetes and diabetic nephropathy-chronic kidney disease. 2018.

22. Fiseha, T., M. Kassim, and T. Yemane, Prevalence of Chronic Kidney Disease and Associated RiskFactors among Diabetic Patients in Southern Ethiopia. American Journal of Health Research, 2014. 2(4): p. 216-221.

23. World population prospects, Popualtion devision, United nations department of Economics and social Affaris. population Division, 2019.

24. Institute JB, Meta-Analysis of Statistics: Assessment and Review Instrument (JBI Mastari). Adelaide: Joanna Briggs Institute 2006. 20032007.

25. Temesgen Fiseha, Mehidi Kassim, and T. Yemane, Prevalence of chronic kidney disease and associated risk factors among diabetic patients in southern Ethiopia. American Journal of Health Research, 2016. 2(4). 
26. David Moher, et al., Preferred Reporting Items for Systematic Reviews and Meta-Analyses: The PRISMA Statement. PloS Medicine, 2009. 6(7).

27. Colin B. Begg and M. Mazumdar, Operating Characteristics of a Rank Correlation Test for Publication Bias. Biometrics, 1994. 50(4): p. 1088-1101.

28. Bekele, M.M., Prevalence and Associated Factors of Chronic Kidney Disease among Diabetic Patients that attend Public Hospitals of Addis Ababa, in Public Health. 2016, Addis Ababa University: Addis Ababa. p. 57.

29. Dawit Worku, Leja Hamza, and K. Woldemichael, PATTERNS OF DIABETIC COMPLICATIONS AT JIMMA UNIVERSITY SPECIALIZED HOSPITAL, SOUTHWEST ETHIOPIA. Ethiop J Health Sci., 2010. 20(1).

30. M. Gizaw, et al., Diabetes mellitus in Addis Ababa, Ethiopia: admissions, complications and outcomes in a large referral hospital. Public Health Action, 2015. 5(1).

31. Solomon Hintsa, et al., Determinants of diabetic nephropathy in Ayder Referral Hospital, Northern Ethiopia: A case-control study. PLoS One, 2017. 12(4).

32. Alemayehu Hussen Geletu, et al., Incidence and predictors of chronic kidney diseases among type 2 diabetes mellitus patients at St. Paul's Hospital, Addis Ababa, Ethiopia. BMC Res Notes, 2018. 11(532).

33. Nikolai C. HodelID, et al., The epidemiology of chronic kidney disease and the association with noncommunicable and communicable disorders in a population of sub-Saharan Africa. PLoS ONE, 2018. 13(10).

34. Andong Ji , et al., Prevalence and Associated Risk Factors of Chronic Kidney Disease in an Elderly Population from Eastern China. Int. J. Environ. Res. Public Health, 2019. 16(4383).

35. Jiayu Duan, et al., Prevalence and risk factors of chronic kidney disease and diabetic kidney disease in Chinese rural residents: a cross-sectional survey. SCIENTIFIC REPORTS, 2019. 9(10408).

36. Aderemi B. Adeniyi, et al., Prevalence of chronic kidney disease and association with cardiovascular risk factors among teachers in Cape Town, South Africa. Clinical Kidney Journal, 2017. 10(3): p. 363-369.

37. OG Egbi, et al., Prevalence and correlates of chronic kidney disease among civil servants in Bayelsa state, Nigeria. Nigerian Journal of Clinical Practice, 2014. 17(5).

38. Wisdom P Nakanga, et al., Prevalence of impaired renal function among rural and urban populations: findings of a cross-sectional study in Malawi. Wellcome Open Research, 2019. 4(92).

39. Laurentia Mihardja and E. Yunir, Prevalence of kidney dysfunction in diabetes mellitus and associated risk factors among productive age Indonesian. Journal of Diabetes \& Metabolic Disorders, 2018. 17: p. 53-61.

40. Hasan Abu-Aishaa, Elwaleed AM Elhassanb, and A.H. Khamisc, Chronic Kidney Disease in Police Forces Households in Khartoum, Sudan: Pilot Report. Arab Journal of Nephrology and Transplantation, 2009. 2(2). 
41. Afolabi MO, et al., Prevalence of chronic kidney disease in a Nigerian family practice population. SA Fam Pract, 2009. 51(2): p. 132-137.

42. Foundation, I.I., The Diabetes Foundation report on implementing national diabetes programmes in sub-Saharan Africa. 2006.

43. Faucu, et al., Harrison's Internal Medicine. 2018.

\section{Figures}

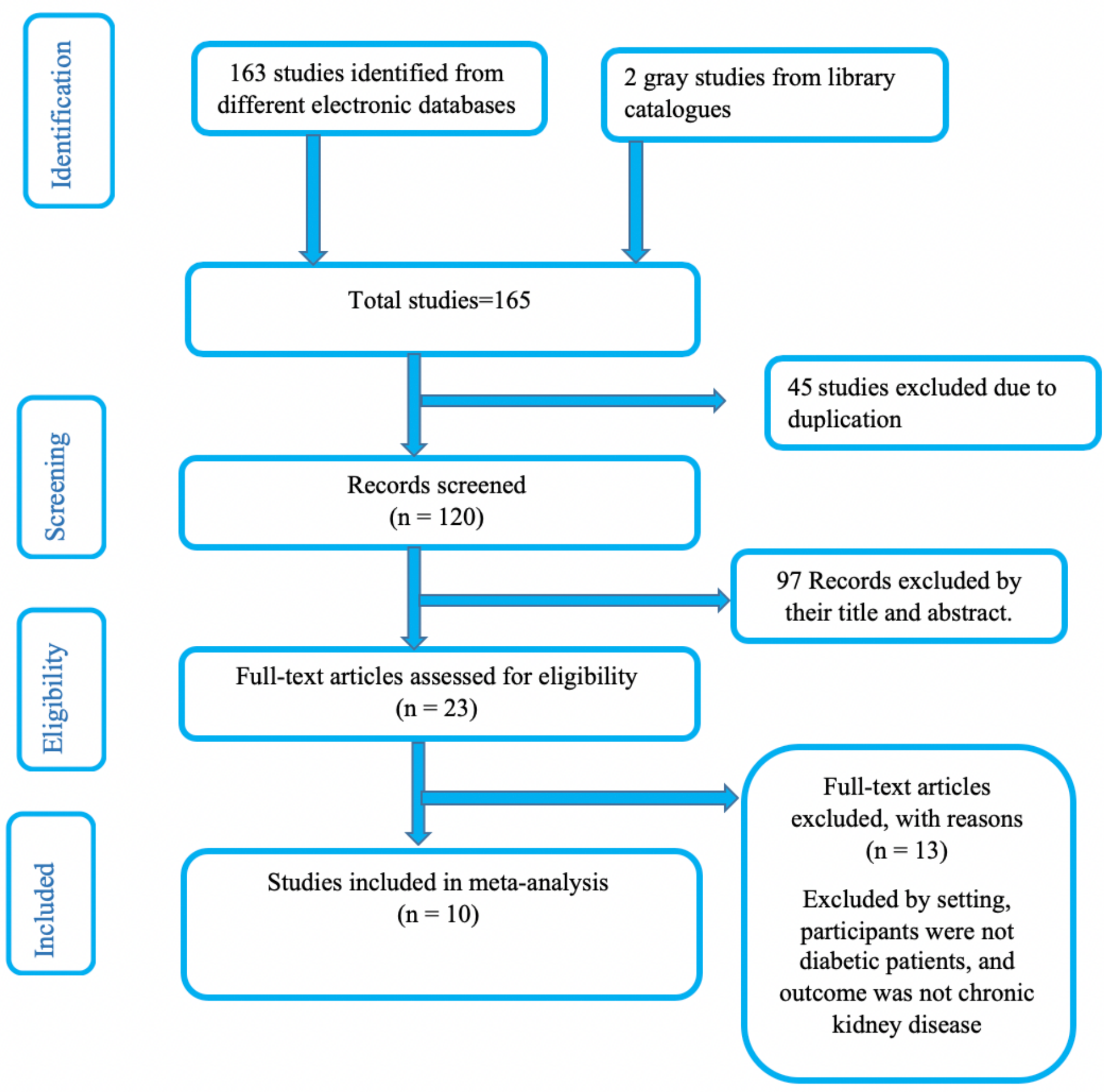


Flow diagram of the studies included in the meta-analysis

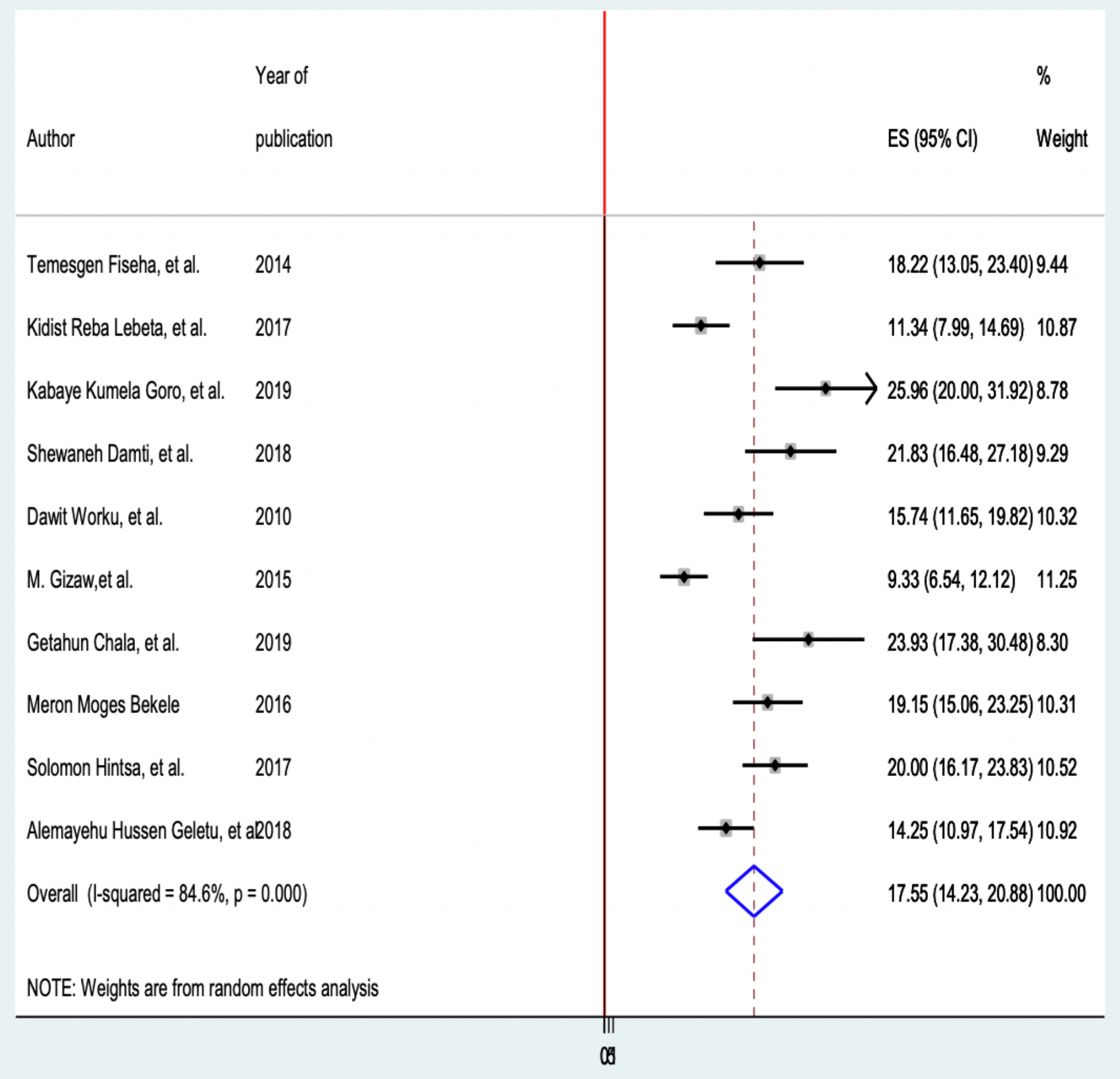

\section{Figure 2}

Forest plot for pooled burden of chronic kidney disease among diabetic patients in Ethiopia, 2020. 


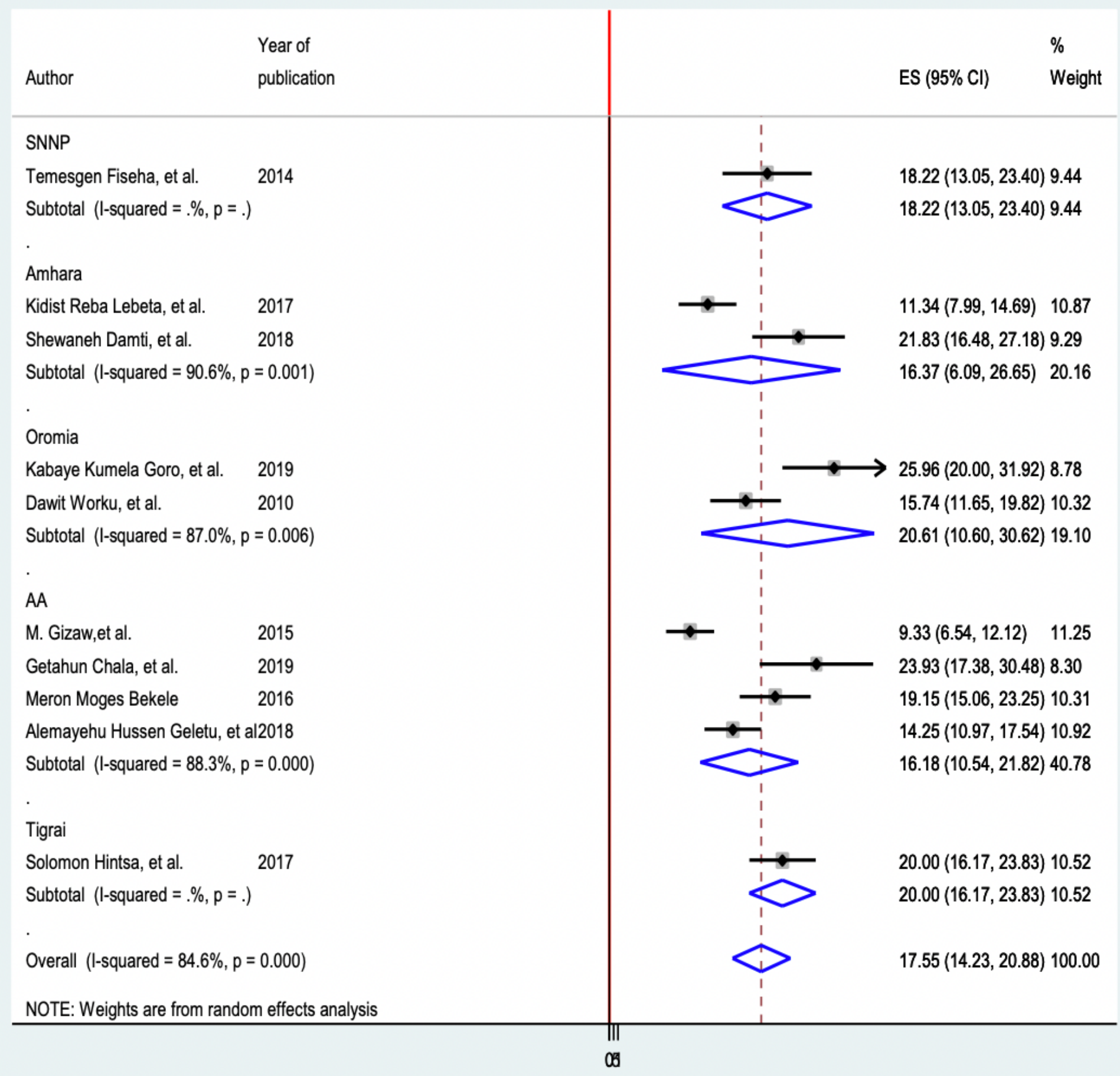

\section{Figure 3}

Sub group analysis based on the region for burden of chronic kidney disease among diabetic patients in Ethiopia, 2020. 
Meta-analysis estimates, given named study is omitted I Lower Cl Limit Estimate

Upper Cl Limit

Temesgen Fiseha, et al. (2014)

Kidist Reba Lebeta, et al. (2017) Kabaye Kumela Goro, et al. (2019)

Shewaneh Damti, et al. (2018)

Dawit Worku, et al. (2010)

M. Gizaw,et al. (2015)

Getahun Chala, et al. (2019)

Meron Moges Bekele (2016)

Solomon Hintsa, et al. (2017)

Alemayehu Hussen Geletu, et al. (2018)

13.484 .23
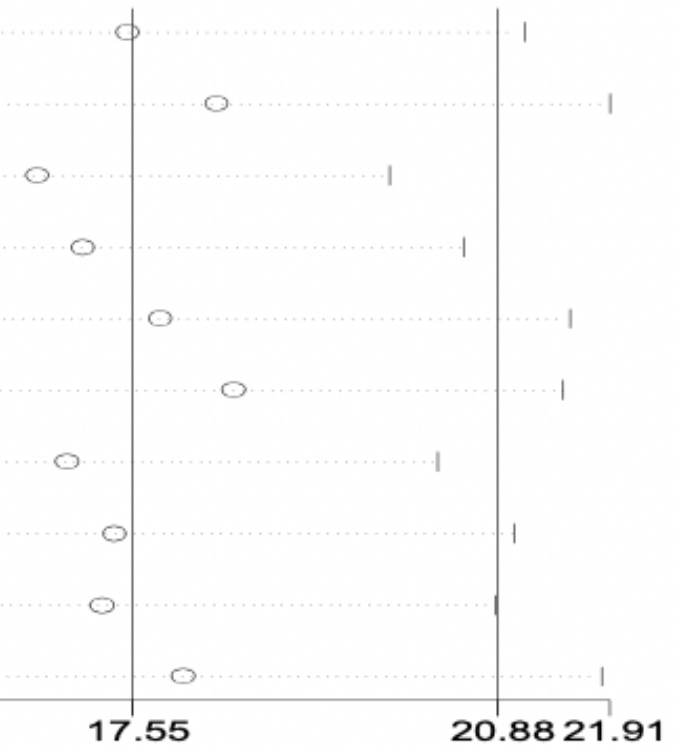

Figure 4

Sensitivity analysis for single study influence on the overall study of burden of chronic kidney disease among diabetic patients in Ethiopia, 2020.

Funnel plot with pseudo $95 \%$ confidence limits

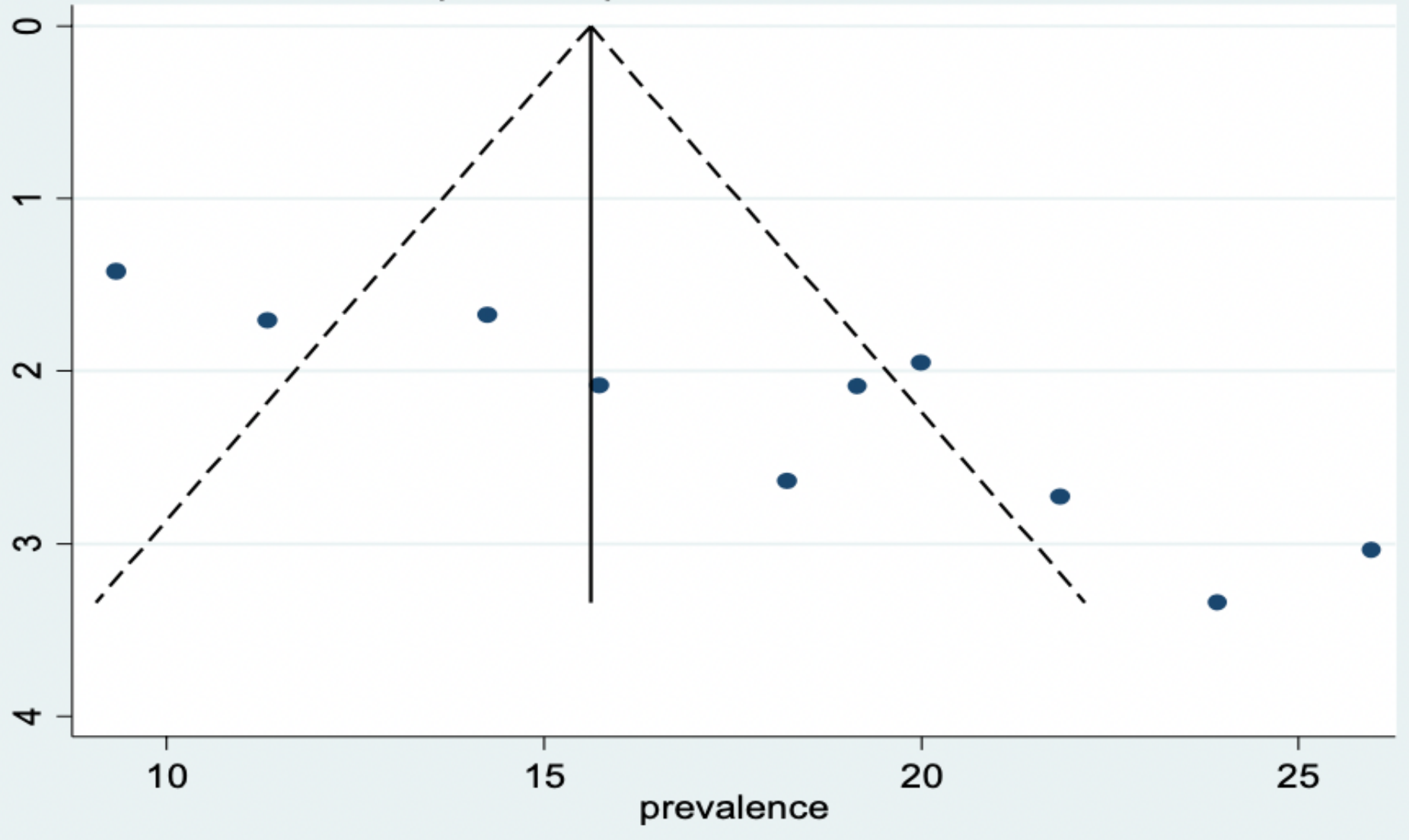


Figure 5

Funnel plot with $95 \%$ confidence limits of the pooled burden of chronic kidney disease among diabetic patients in Ethiopia, 2020.

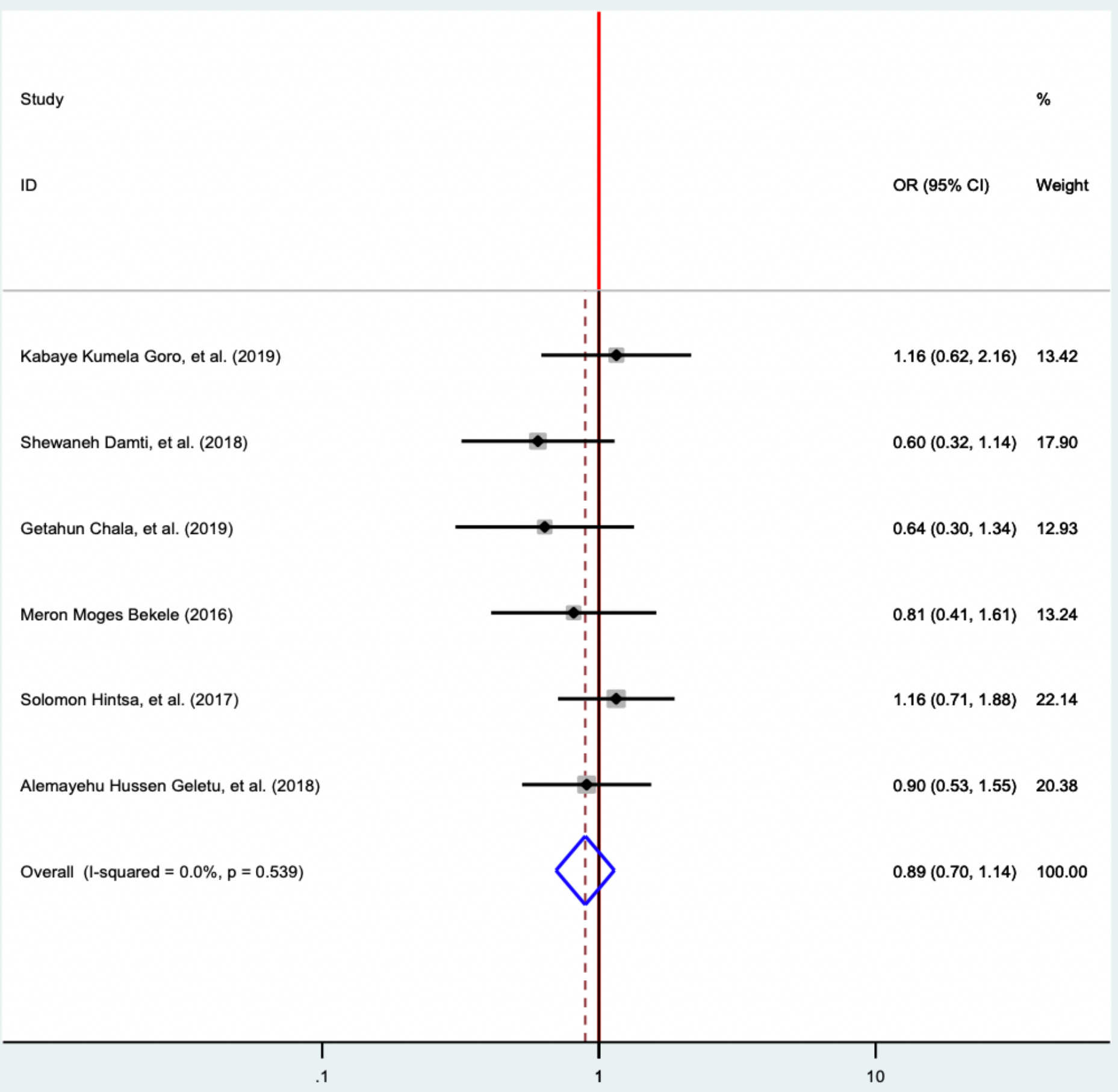

\section{Figure 6}

Forest plot for pooled effect sex on chronic kidney disease among diabetic in Ethiopia, 2020. 
ID

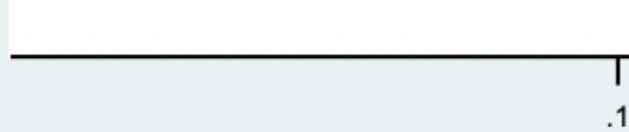

\section{Figure 7}

Forest plot for pooled effect hypertension on chronic kidney disease among diabetic in Ethiopia, 2020. 
ID

OR $(95 \% \mathrm{Cl}) \quad$ Weight

Shewaneh Damti, et al. (2018)

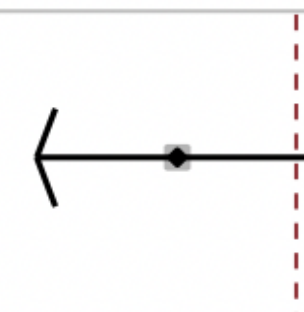

Meron Moges Bekele (2016)

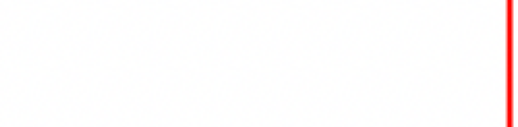

Solomon Hintsa, et al. (2017)

\begin{tabular}{l} 
Overall (I-squared $=73.1 \%, \mathrm{p}=0.024)$ \\
NOTE: Weights are from random effects analysis \\
\hline \\
.1
\end{tabular}

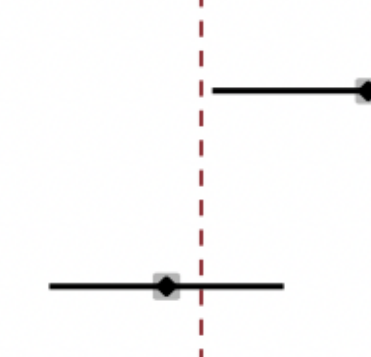

$0.83(0.35,1.96) \quad 30.99$

$0.17(0.08,0.37) \quad 32.98$

Solomon Hintsa, et al. $(2017)$

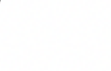
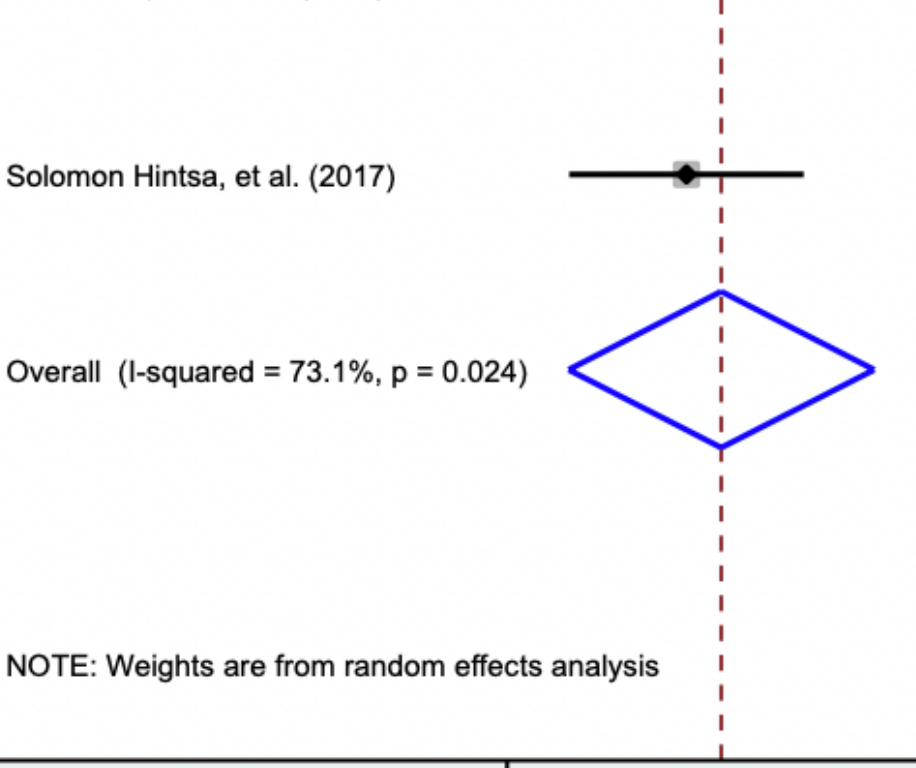

.1

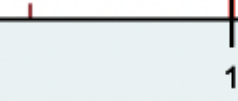

$0.27(0.14,0.52) \quad 36.03$

$0.33(0.14,0.76) \quad 100.00$

\section{Figure 8}

Forest plot for pooled effect of types of DM on chronic kidney disease among diabetic in Ethiopia, 2020. 
ID

OR $(95 \% \mathrm{Cl}) \quad$ Weight

Kabaye Kumela Goro, et al. (2019)

Meron Moges Bekele (2016)

Overall (I-squared $=0.0 \%, p=0.515$ )

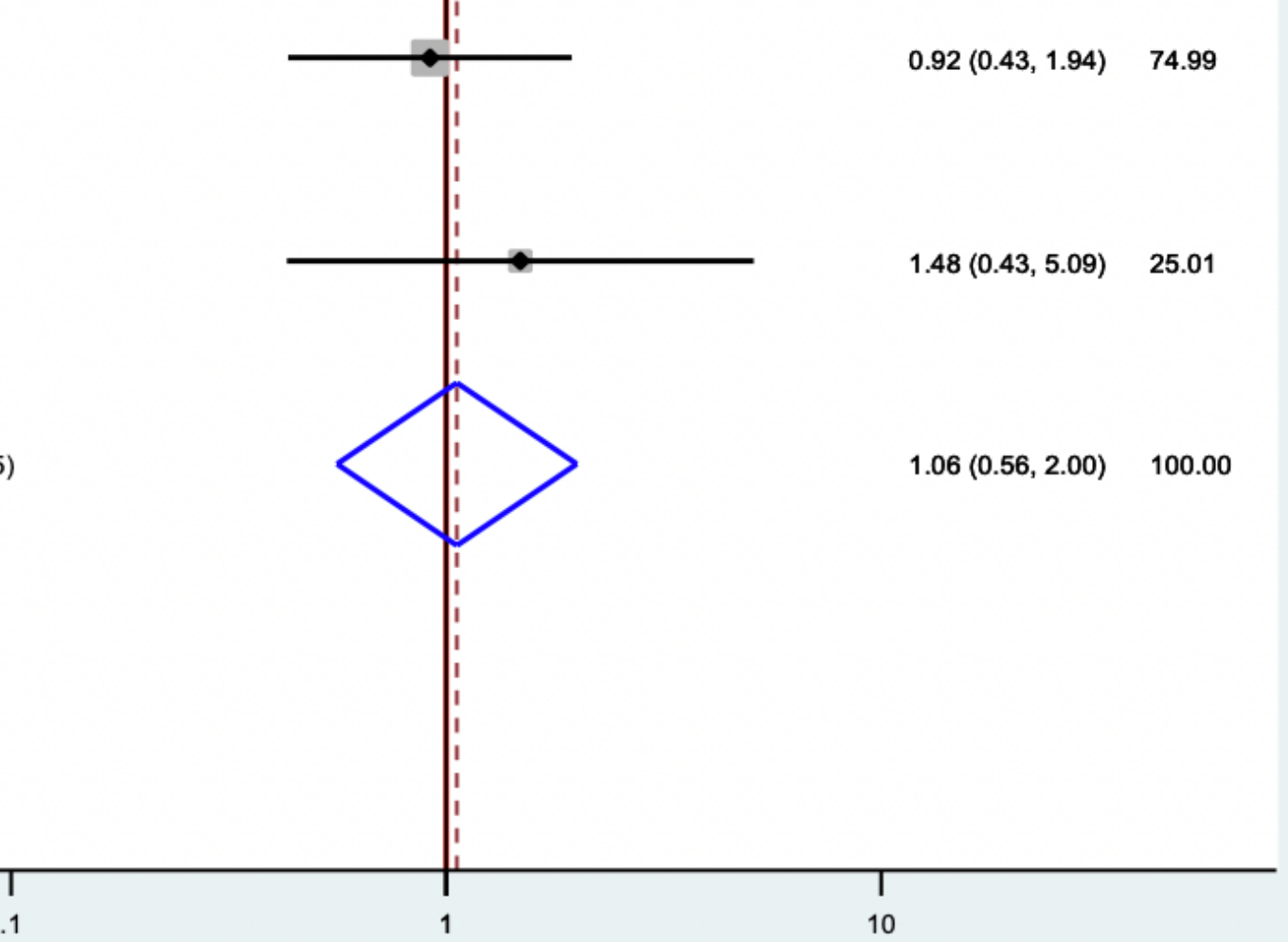

\section{Figure 9}

Forest plot for pooled effect of family history of kidney disease on chronic kidney disease among diabetic in Ethiopia, 2020. 
Study

ID

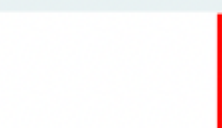

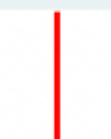

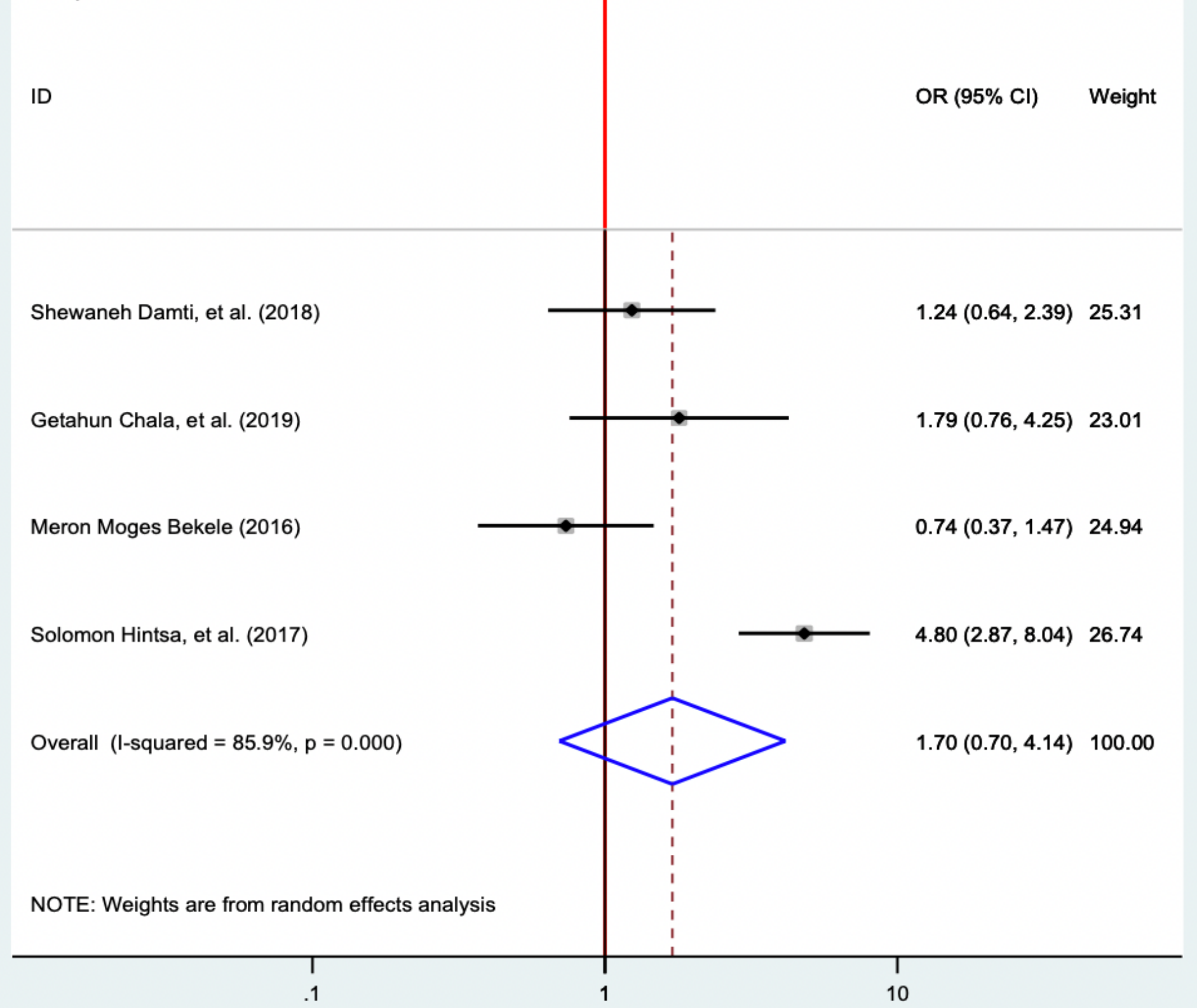

Figure 10

Forest plot for pooled effect of BMI on chronic kidney disease among diabetic in Ethiopia, 2020. 
ID

OR $(95 \% \mathrm{Cl}) \quad$ Weight

Kabaye Kumela Goro, et al. (2019)

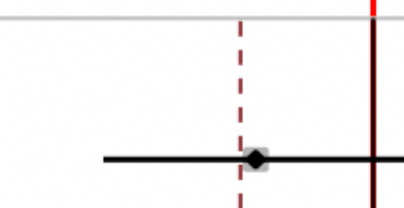

$0.55(0.26,1.19) \quad 27.18$

Shewaneh Damti, et al. (2018)

Meron Moges Bekele (2016)

Overall $(\mathrm{I}-$ squared $=0.0 \%, \mathrm{p}=0.378$ )

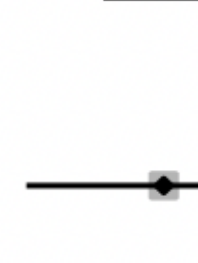

I

1

$.35(0.17,0.70) \quad 40.98$

$0.69(0.35,1.37) \quad 31.84$

(a)

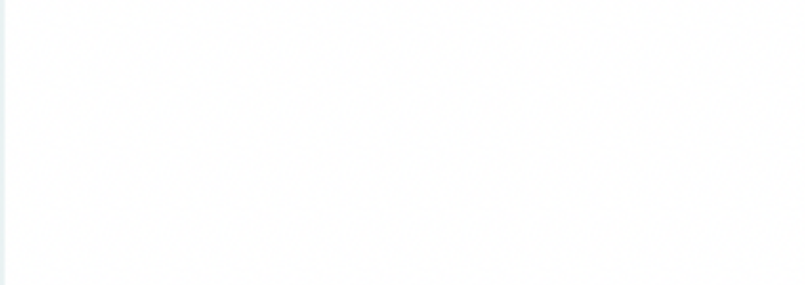

1

.1

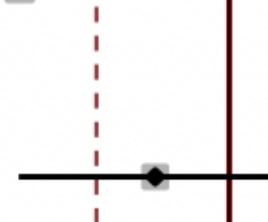

$0.51(0.34,0.77) \quad 100.00$

\section{Figure 11}

Forest plot for pooled effect of duration of patient stayed with DM on chronic kidney disease among diabetic in Ethiopia, 2020. 
ID

OR $(95 \% \mathrm{Cl}) \quad$ Weight

Shewaneh Damti, et al. (2018)

Meron Moges Bekele (2016)

Solomon Hintsa, et al. (2017)

Alemayehu Hussen Geletu, et al. (2018)

Overall $($ I-squared $=79.5 \%, p=0.002$ )

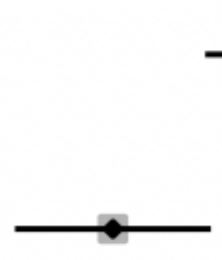

$1.87(0.85,4.11) 23.91$

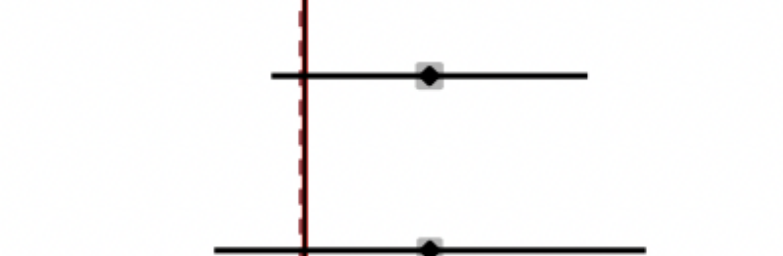

$1.87(0.64,5.49) 19.42$

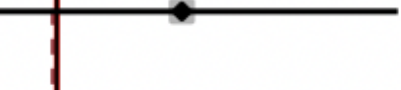

$0.40(0.25,0.66) 28.69$

$0.90(0.53,1.55) 27.98$

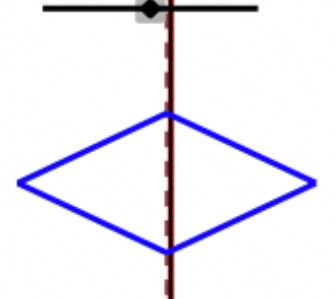

$0.98(0.47,2.06) 100.00$

NOTE: Weights are from random effects analysis

1

1

1

Figure 12

Forest plot for pooled effect of alcohol consumption on chronic kidney disease among diabetic in Ethiopia, 2020.

\section{Supplementary Files}

This is a list of supplementary files associated with this preprint. Click to download. 
- dataset.xIsx

- PRISMAchecklist.doc 